\title{
A FORMAÇÃO CONTINUADA DE PROFESSORES/AS DA EDUCAÇÃO BÁSICA VIA ESTÁGIO CURRICULAR SUPERVISIONADO OBRIGATÓRIO*
}

\author{
Willian dos Santos Bonfim (ETEC) \\ Andréia Nunes Militão (UEMS)
}

\section{Introdução}

O presente capítulo deriva de pesquisa de mestrado intitulada "Contributos do estágio curricular supervisionado obrigatório para a formação continuada de professores/as da educação básica" (BONFIM, 2020) e busca analisar a aprendizagem na docência durante o efetivo exercício da profissão, pelos professores da escola com participação no Estágio Curricular Supervisionado Obrigatório (ECSO) proposto por um curso de licenciatura em Física da Universidade Estadual Paulista (UNESP).

Caracterizar a aprendizagem da docência em vias das ações do próprio trabalho docente, possibilita acentuar perspectivas formativas para além da formação acadêmica inicial, que atendam, inclusive, os professores em efetivo exercício da profissão ao estabelecer-se uma aprendizagem de construção configurada como contínua.

Neste sentido, Contreras (2002) salienta que a inserção ao debate das ações de formação de docentes, incluam os próprios professores, pois como tal, compartilham de vivências e experiências que podem contribuir para uma estruturação realmente adequada. Tem-se assim que, como parte dos sujeitos primordiais dos processos de aprendizagem da profissão docente estão, por vezes, os próprios professores da escola básica, uma vez que se encontram capazes de presenciarem as necessidades formativas advindas da atividade.

E neste matiz, Antunes (2018, p. 34) sinaliza que a aprendizagem contínua da "docência na docência" compreender-se-á como dever do educador, visto que acentua-se no princípio do aprender e ensinar como ato humano em constante desenvolvimento durante a vida, ao passo em que ao respeitar-se as individualidades, intenciona-se proporcionalmente as necessidades da prestação do ensino.

${ }^{*}$ DOI - 10.29388/978-65-86678-68-0-0-f.133-152 
O presente estudo se pauta na compreensão de que a escola se faz como espaço necessário e ideal aos processos formativos da docência. $E$ ainda, é na escola que se encontram os vários agentes e sujeitos dos processos formativos da docência, dentre as quais inserem-se as instituições de ensino superior, os professores da universidade, os alunos do estágio curricular supervisionado obrigatório, e por fim, o professor da escola e demais atores desta instituição.

Assim, importa buscar o Estágio Curricular Supervisionado Obrigatório para além de uma mera composição curricular nos cursos de formação de professores, permitindo sua inserção como processo formativo do desenvolvimento profissional do docente em exercício friccionados nos momentos oficiais e não oficiais dos espaços-tempo constituídos para seu cumprimento.

Sarti e Araujo (2016) obtêm alguns indícios de que as relações estabelecidas entre os professores e os estagiários apresentaram "efeitos ascendentes" (SARTI, 2009) de tal forma que se pode considerar o estágio curricular supervisionado obrigatório como processo formativo para ambos os sujeitos. De mesma forma, Aroeira (2007) reafirma a possibilidade do estágio como formação contínua dos professores da escola e enquanto processo de construção de saberes dos estagiários. Para isso, acrescenta a necessidade de um projeto que promova a reflexão da atividade docente, tanto individual como coletivamente, principalmente utilizando-se da confrontação teórica.

O mesmo argumento é defendido por Dias e Vieira (2012) ao afirmarem que assim como um processo formativo formal, a assemelhar-se com a formação contínua, o processo de estágio curricular supervisionado deve colaborar na promoção de uma relação em que se cria condições para o desenvolvimento da capacidade de atuação, de mobilidade e mudança dos professores por meio da reflexão e análise dos desafios da educação, das práticas de sala de aula e dos desafios da contemporaneidade. Pimenta (2006) defende a combinação entre formação inicial, exercício profissional, todas as experiências próprias individuais e dos demais sujeitos do processo, as condições teórico-epistemológicas sobre a prática docente e a dimensão educacional, para atuarem no sentido de uma formação contínua pela reflexão. De tal forma, tais condições favorecem o aprimoramento individual e o desenvolvimento profissional.

Logo, uma formação contínua com a explicitação das demandas da prática, das necessidades dos professores de se anteporem aos conflitos e dilemas da atividade docente podem transcorrerem a partir de ações do 
trabalho coletivo articulado, embasado e fundamentado teoricamente provenientes do processo de estágio curricular supervisionado obrigatório dos cursos de licenciatura (PIMENTA, 2006).

$\mathrm{E}$, uma vez que se estabeleça o estágio curricular supervisionado obrigatório como processo formativo contínuo na docência em exercício de professores das escolas de educação básica, admitir-se-á uma formação inicial que não se encerra no curso de formação de professores. Por vez, a formação contínua, por vias do estágio curricular supervisionado não dever-seá compreender como treinamento ou capacitação meramente. Sua articulação deve envolver as instâncias formadoras, colaborativamente e de forma ativa (PIMENTA, 2006).

Se por um lado, acentua-se o ECSO como espaço-tempo para formação continuada de professores da escola de educação básica, por outro, assenta-se a escola como ambiente que faz parte deste processo formativo. A escola é ambiente nutrido de condições que incluem o devido potencial formativo de professores experientes tanto quanto de estagiários, principalmente quando se compreende uma escola e seus professores capazes de racionalizarem os processos do ensino (PIMENTA, 2006).. Também, interessa incentivar ações em que os professores como pesquisadores de suas próprias práticas, reafirmarão a perspectiva da reflexão no exercício da docência, acentuando a escola como local de formação contínua em que se valorizará seus docentes e os saberes ali postos e mobilizados.

A partir do exposto, questiona-se: 0 que aprendem os professores da escola que participam ou participaram de experiências de estágio curricular supervisionado?

\section{Aportes Metodológicos}

Uma característica observada nas pesquisas em educação está na utilização recorrente dos termos "qualitativo" e "quantitativo" para indicar as diferentes formas de se efetuar o processo investigativo. André (1991) e Lüdke (1988) já apontavam para tais associações e salientavam que estas especificações recorrentemente voltavam-se para definições de posturas filosóficas e não para técnicas de coleta. Logo, tornavam-se quase irremediáveis as distorções e incompreensões quanto ao estado das ações e dos processos investigativos relacionados à pesquisa definida em tais termos.

A abordagem qualitativa evidência a relação sujeito e objeto, no sentido de que ambos representam a mesma natureza (MINAYO \& SAN- 
CHES, 1993). De tal forma, define-se o sujeito e o objeto na perspectiva de suas intenções, dos vários aspectos de suas motivações, no que diz respeito a atuação dos atores, das condições e relações de poder e conflito, além de processos que tangem a cognição. Gunther (2006) considera a abordagem qualitativa na perspectiva da "compreensão do complexo", das "complexidades das relações" em busca de uma "construção do real", em si compreendido na perspectiva dos sujeitos que a compõe.

Por consequência das variadas técnicas de coleta atribuídas às pesquisas sob nossa ótica, atribuída como abordagem qualitativa, problematiza-se a entrevista utilizada como metodologia de coleta e os processos de análise por Núcleo de Significados.

Lüdke e André (1986) afirmam que as entrevistas, principalmente as semiestruturadas permitem a interação entre pesquisador e pesquisado em uma perspectiva que não se faz hierárquica, mas sim recíproca, pois "Uma entrevista bem-feita pode permitir o tratamento de assuntos de natureza estritamente pessoa e íntima, assim como temas de natureza complexa e de escolhas nitidamente individuais" (LÜDKE \& ANDRÉ, 1986, p. 34).

A "entrevista semiestruturada" é formulada em questões abertas, que permitem ao informante deliberar interpretações e respondê-las com boa articulação. $O$ questionador também poderá refazê-las no sentido de ampliar as condições do melhor entendimento dos enunciados (BELEl, et.al 2008). Desta forma, o entrevistador poderá promover novas interrogativas na medida em que o informante pronunciar suas respostas. Ainda sobre as questões que compreendem o roteiro da entrevista semiestruturada, "Elas são resultados não só da teoria que alimenta a ação do investigador, mas também de toda a informação que ele já recolheu sobre o fenômeno social que interessa, não sendo menos importantes seus contatos, inclusive, realizados na escolha das pessoas que serão entrevistadas" (TRIVIÑOS, 1987, p. 146).

As perguntas direcionadas na entrevista foram objetivas segundo o roteiro organizado em eixos que buscaram atender os objetivos específicos da pesquisa. Os eixos oportunizaram a determinação do perfil e formação docente, o entendimento das relações entre as instituições de ensino (escola e universidade), das relações entre os sujeitos destas instituições, a compreensão das condições de atual no estágio, as concepções dos professores sobre o estágio, a melhor compreensão das vivências e experiências da docência pelo professor, e por fim, de propostas de melhoria sobre o estágio.

A transcrição das respostas fora realizada em software de edição de texto e padronizou- se em estrutura de tabulação em linhas que continham 
a sequência "pergunta-resposta". Este procedimento, da transcrição, levou em média uma semana para cada entrevistado. Posteriormente, realizou a leitura detalhada do texto transcrito, observando-se os cuidados com a supressão de termos, pausas e prestando a devida atenção as semânticas que compunham as falas dos entrevistados visto a necessidade de não haver prejuízos a metodologia de análise por Núcleo de Significações.

Para a realização de uma análise de entrevistas optou-se pelo uso do Núcleo de Significações, compreendendo o sujeito enquanto ser complexo, que estabelece múltiplos parâmetros de captação, interpretação e reordenação de sua noção da realidade. Na compreensão de seus modos, entende-se que o sujeito se expressa ao mundo atribuindo suas relações sociais tanto quanto sua subjetividade, ou seja, articula-se em uma relação de mediação entre contrários (AGUIAR e OZELLA, 2013).

Ao projetar a razão em uma ação pelo sujeito, não é por vez demasiado simplório, uma vez que "O pensamento passa, portanto, por muitas transformações para ser expresso em palavras, de modo a concluir-se que a transição do pensamento para a palavra passa pelo significado e o sentido (AGUIAR \& OZELLA, 2013, p. 304). Segundo Aguiar e Ozella (2006) deve-se compreender o pensamento carregado por emoções e sentimentos, que de forma, expressa-se na palavra com significado.

Para Aguiar e Ozella (2013) os significados representam a forma como transformamos o natural (o externo) em cultural (próprio). Os significados podem ser partilhados e socializados por meio da linguagem e seus signos. Assim, "Os significados referem-se, assim, aos conteúdos instituídos, mais fixos, compartilhados, que são apropriados pelos sujeitos, configurados a partir de suas próprias subjetividades" (AGUIAR \& OZELLA, 2006 , p. 226). Para tal, deve-se entender que os signos são instrumentos da linguagem, e representam o meio pelo qual o sujeito externaliza-se, mas também se articula com sua própria consciência. Desta forma "A palavra, signo por excelência, representa o objeto na consciência" (AGUIAR \& OZELLA, 2013, p. 303).

Para Aguiar e Ozella (2006, p. 226), "Dessa forma, podemos afirmar que a compreensão da relação pensamento/linguagem passa pela necessária compreensão das categorias significado e sentido". Somente em um processo de análise e interpretação na articulação dialética do pensamento com a linguagem, que poder-se-á atingir zonas mais profundas da constituição do sujeito, aproximando-se assim das "zonas de sentido" (AGUIAR \& OZELLA, 2013, p. 304). 
A primeira etapa da análise deve compreender uma leitura fluente, assim como uma organização do material, expresso nesta pesquisa, pelos textos transcritos das entrevistas. Neste processo de leitura do texto, busca-se coletar palavras significativas, carregadas de significados, pois "Assim, temos que partir das palavras inseridas no contexto que thes atribui significado, entendendo aqui como contexto desde a narrativa do sujeito até as condições histórico-sociais que o constituem" (AGUIAR \& OZELLA, 2006, p. 230). Esta etapa possibilitará elencar o que se denomina por "pré-indicadores", que são as "palavras-chaves" que expressam pensamento e linguagem e, portanto, compõem um significado (AGUIAR; SOARES; MACHADO, 2015). Por fim, "Geralmente, esses pré-indicadores são em grande número e irão compor um quadro amplo de possibilidades para a organização dos núcleos" (AGUIAR \& OZELLA, 2006, p. 230). Realizase um segundo processo de leitura, agora sobre os pré-indicadores, de forma a aglutiná-los em conjuntos, chamadas de indicadores. A aglutinação poder ser realizada segundo critérios de similaridade, oposição ou complementaridade. Desta forma, haverá uma fusão de várias palavras e termos, que constituído o "termo indicador", expressará não apenas uma ideia complexa, mas conterá todos os elementos distintos desta ideia. Tal processo resultará em certa quantidade de agrupamentos e assim menor será a diversidade destes indicadores.

Deve-se retornar ao texto, buscando selecionar os trechos que ilustra e afirmam os termos indicadores. Neste momento, o recorte ao texto se faz como própria metodologia, e logo, "Esse momento já caracteriza uma fase do processo de análise, mesmo que ainda empírica e não interpretativa, mas que ilumina um início de nuclearização" (AGUIRA \& OZELLA, 2006, p. 230).

Para Aguiar, Soares e Machado (2015), a terceira e última parte do tratamento aos dados é a que mais aproxima-se do sentido atribuído a realidade pelo sujeito. Nesta fase, objetiva-se a formação dos chamados "núcleos de significação". Este são agrupamentos maiores, representam a articulação dos termos indicadores, que por sua vez, constituem-se pelos préindicadores já agrupados pelos critérios de similaridade, complementaridade e contraposição na primeira etapa anterior.

De tal forma, os núcleos de significados devem, possibilitar a análise das condições subjetivas, os contextos diversos, e a possível visualização da construção dos sentidos, de tal forma que "Os núcleos resultantes devem expressar os pontos centrais e fundamentais que trazem implicações para o sujeito, que o envolvam emocionalmente, que revelem as suas de- 
terminações constitutivas" (AGUIAR \& OZELLA, 2006, p. 231). Ainda, a constituição dos sentidos e significados deve ser marcado por um processo de idas e vindas, incluindo-se nelas, as etapas anteriores (AGUIAR; SOARES; MACHADO, 2015, p. 63).

Finalmente, pela análise dos núcleos de significados, faz-se possível revelar o movimento do sujeito. Ainda assim, faz-se necessário administrar demais aspectos, como a compreensão do contexto afetivo, cultural, e socioeconômico, bem como dos aspectos metodológicos de uma pesquisa científica, que em base, recorrerá também à luz dos referenciais teóricos.

\section{Contributos Formativos do Estágio Supervisionado para os Professores da Escola Básica}

Dentre os sujeitos envolvidos na oferta do Estágio Curricular Supervisionado Obrigatório, apesar de sua parcial obliteração em vista a ênfase aos alunos estagiários, está o professor da escola de educação básica. E no Brasil, a figura do professor ainda se faz pouco especificada no que se remete aos processos formativos do estágio curricular supervisionado (BENITES; SARTI; NETO, 2015).

Desta forma, os professores da escola mostram-se como agregadores de saberes, dotados de experiências deste universo profissional (BENITES; CYRINO, NETO, 2012; BENITES; SARTI, NETO, 2015). Em suma, "Esse professor também é um profissional com sólida formação teórica, compromisso e sensibilidade social e humana com vistas a contribuir na superação das desigualdades educacionais" (PIMENTA \& LIMA, 2019, p. 10).

Parte-se, então, para a entrada do estagiário na escola, em busca do atendimento de características que dizem respeito a essencialidade formativa da identidade profissional docente. Cada instituição envolvida nesta etapa apresenta suas significações sobre o ECSO, e para a instituição de ensino superior tais se fazem presentes em seus projetos pedagógicos dos cursos de licenciatura, nas suas estruturas curriculares e organizacionais No entanto, para que esta compreensão se apresente em maior completude, faz-se necessário entender a formação do futuro professor como um processo compartilhado, em que não há exclusividades formativas, mas que há demandas que não são simplórias. Assim, "Partilhar o trabalho docente pressupõe propor e realizar conjuntamente atividades docentes que redundem em qualificação tanto do trabalho quanto da formação dos que estiverem envolvidos no processo" (CALDERANO, 2013, p. 10). 
Contudo, é pertinente estabelecer-se a dimensão do trabalho docente do professor da escola na articulação das orientações, dos saberes discutidos e das experiências a serem compartilhadas durante o ECSO. E assim, diante das suas condições enquanto atuante no estágio, Calderano $(2013$, p. 06) ainda salienta para o atendimento das expectativas e iniciativas individuais e institucionais. Ainda que não seja exclusiva a sua responsabilidade diante a formação profissional dos estudantes de licenciatura enquanto processo do ECSO, percebe-se numerosas indicações e características relativas a suas ações como formador de professores. Algumas expressões corroboram para o entendimento do docente enquanto formador de outros professores. Normalmente, durante o processo do ECSO, o docente apresenta-se associado como tutor, mentor, professor-associado, participante, orientador, parceiro (BENITES, SARTI e NETO, 2015, p. 105). Destas definições, chama-se atenção para o professor da escola como "professor colaborador".

Dentre alguns aspectos dos professores da escola nesta posição, Cyrino, Cerignoni e Neto (2015) atentam para a orientação suficientemente "passiva", em que se propõem aos estagiários a prática de uma observação apática e tanto quanto estagnada, estabelecendo uma perspectiva do apenas "saber-fazer suficiente".

Segundo Benites, Sarti e Neto (2015, p. 106), muitos dos professores que colaboram com o processo formativo do estágio curricular supervisionado obrigatório apresentam, de certa forma, pouca clareza sobre seu papel na formação docente de futuros professores. De certa forma, a compreensão sobre sua participação na formação docente é deixada de lado em relação aos processos diários e as tarefas profissionais cotidianamente envolvidos.

Como expressa Lima (2008), deixa-se de pensar o trabalho universidade-escola como comum no objetivo da formação de professores quando o espaço-tempo formativo da escola e seus contextos são, muitas vezes, atravessados por condições conflitantes de trabalho.

Ainda, de forma geral, as ações do professor da escola são negligenciadas por parte dos profissionais docentes das instituições de ensino superior proponentes do estágio. A ausência de diálogo entre professores da escola e os da universidade obstruem, de certa forma, uma parceria concreta e efetiva entre as instituições formadoras dos estagiários - universidade e escola (CAIRES et. al, 2011; CALDERANO, 2013). Assim, "Esses professores costumam ser deixados a sua própria sorte diante dos estagiários e pouco 
se sabe sobre o modo como efetivamente elaboram o trabalho que então desempenham" (SARTI \& ARAÚJO, 2016, p. 176).

Por fim, pode-se generalizar que quase a totalidade dos professores que atuam no estágio fazem-no sem que para tal possuam algum tipo de formação específica, cursos, ou participem de capacitações. E desta forma, “No Brasil, não existe uma política nacional para a formação do PC, apenas iniciativas locais e acordos tácitos, pautados em uma dimensão afetivo-social que tenta suprir as necessidades vinculadas ao processo de estágio" (CYRINO; BENITES, NETO, 2015, p. 257).

Na sequência, analisa-se o olhar do Professor da Escola de Educação Báscia (PEB01) constituída pela compreensão de seus 9 núcleos de significados. Sobre este professor, como sujeito histórico, evidenciou detalhes sobre sua investidura em um curso de licenciatura e o posterior ingresso da profissão docente, pois "[...] quando eu terminei o terceiro colegial, eu não tinha vontade em ser professor" (PEB01).

A escola de educação básica, local do trabalho docente, é apresentada como instituição fundamental para a formação do futuro professor, e em que pesa as ações do professor da escola enquanto seu coformador. É a escola capaz de mostrar as condições reais da educação, que apesar de sua frágil condição estrutural, permite ao estagiário vivências confluentes com a construção de uma identidade profissional docente.

\begin{abstract}
Pra mim o papel da escola no processo de formação do estagiário é possibilitar experiências e possibilitar experiências mais diversas possíveis, pelo menos os de regência são 40 horas, pra quem está na Universidade parece que é muito, 40 horas, mas são 40 horas dividido em duas horas semanais durante um ano e isso é pouco para depois quando você entra dentro de uma sala de aula e você tem que trabaIhar 40 horas semanais (PEB01).
\end{abstract}

O Estágio Curricular Supervisionado Obrigatório e suas atividades realizadas na escola, proporcionam experiências necessárias ao estagiário para que este compreenda o contexto real das atividades profissionais. Ainda assim, não pode o ECSO ser reduzido como aplicabilidade ou parte prática inicial da docência, como no trecho anunciado pelo PEB01 em que "Algumas coisas que por mais que a gente vê e tem acesso na Universidade, na escola básica é como se fosse aquela teoria toda sendo colocada em prática". E nesta compreensão separa-se a universidade enquanto suporte teórico e a escola como suporte a prática. 
E isso é um problema, com certeza é um problema, porque talvez o professor esteja ali (da universidade) com alguns objetivos, algumas metas que eu não consiga contribuir para atingir, mas sem nem saber porque eu não sei exatamente quais são os objetivos, as metas deles. E a visão dele lá dentro da Universidade é uma e a minha dentro da escola é outra (PEB01).

Galindo e Abib (2012), consideram que para um agir comunicativo entre os professores das duas instituições atuantes em uma mesma perspectiva de formação dos estagiários, necessário se faz o compartilhamento de objetivos e a atuação em um trabalho colaborativo, pois "Eu acho que tudo depende de como o estágio é trabalhado pelo professor da Universidade e pelo professor da escola básica [...]" (PEB01). No entanto, sente-se que a escola básica e seu professor apresentam uma compreensão simplória de formação do licenciando, e que de certa forma, a condição da universidade se faz mais qualificada, e, por fim, superior como no trecho "[...] então nós poderíamos juntos conseguir algo melhor, mas isso não acontece, poderia acontecer inclusive, mas não sei parece que a escola é tida como uma instituição menor e a Universidade como uma instituição maior" (PEB01). E atrelado a tal compreensão, perpetua-se a concepção de que o ECSO se faz como processo vetorizado em um sentido único "universidade para a escola".

Contudo, há de se compreender que o professor da escola básica buscou conceder autonomia suficiente aos estagiários, por entender que "Porque essa, inclusive, é uma das... não sei se... não colocaria a palavra exigência da universidade em si, mas assim, algo importante pra formação deles, né?" (PEB01). Desta forma, ao atender as necessidades apresentadas pelos estagiários, mostrou-se empenhado em testar suas formas de orientação no ECSO como no trecho "Inclusive, que eles falam mesmo, então por isso que eu estou testando" (PEB01).

Assim, as ações do professor da escola além de incluírem o desenvolvimento de aulas, o planejamento e a busca por metodologias adequadas dentro das atividades a serem desenvolvidas no ECSO junto aos estagiários, fazem-se ainda, preocupadas no atendimento de outras diretrizes, que por vezes externam-se das atividades do estágio, como anunciado na explanação "Sempre tento ajudar o máximo que eu posso, tanto nas aulas como, às vezes, essa semana eles tiveram que apresentar um seminário, aí eles precisaram de uma certa ajuda, daí a gente sentou para montar esse seminário, ajudei eles" (PEB01). 
Ainda, aponta-se como proposta de ação no ECSO pelo PEB01 o trabalho baseado no exercício da reflexão pelo estagiário, condicionado na mobilização da teoria apreendida na universidade e sua a colocação prática na escola pública, e reafirmando o exposto por Cyrino e Neto (2013), de uma forma de acompanhamento que segue o modelo observação, participação e regência. No entanto, desvelou-se em sua exposição, que há planejamento de atividades envolvendo o professor da escola e o estagiário, e que ocorrem, inclusive, em reuniões realizadas na escola como afirmado na fala "E nessa reunião nós geralmente discutimos sobre o planejamento de aula da semana seguinte e retomamos as aulas da semana" (PEB01). Notase também sua periodicidade, pois "A reunião acontece toda sexta, das duas às quatro, então ela dura duas horas e ela acontece na escola, lá na Arno Hausser" (PEB01), no entanto, não é possível afirmar que se trata de reuniões destinadas aos estagiários do ECSO, uma vez que há nesta escola a presença do programa Residência Pedagógica e suas exigências.

Ainda, as atividades que são discutidas e planejadas incluem as avaliações destinadas aos alunos da escola, e a organização das sequências didáticas a serem lecionadas tanto pelos estagiários quanto pelo professor da escola, pois "Geralmente a gente tem essa ação meio que... sabe? Interativa, uma hora eu, uma hora eles, enfim, dentro da sala de aula. E daí pra conseguir fazer isso é necessário que, tenha um planejamento antes" (PEB01). Mostrou-se ainda que as ações são de certa forma, individualizadas e realizadas pelos estagiários a pedido do professor, como aponta o trecho "Os estagiários regentes ainda mais, porque eles planejam a aula e já levam o planejamento pronto, só pra gente discutir lá no dia [...]" (PEB01). Assim, realça-se o pensamento de Benites, Cyrino e Neto (2012) de que o professor da escola básica se faz profissional capaz de atuar no ensino dos alunos regulares, mas que se encontra também em um agir formativo ao receber estagiário.

Evidenciou-se a tradição de que devem ser atribuídos aos estagiários a condição de buscarem ativamente as escolas para a realização do estágio. Sua seleção segue por critérios pessoais dos estagiários, como condições de transporte, e proximidade entre a escola alvo e o endereço de residência do estagiário. Se por um olhar, mostra-se que o estagiário se objetiva da escolha pela escola, é também por sua abordagem direta ao professor da escola que se iniciam as relações do Estágio Curricular Supervisionado Obrigatório, não havendo na escola qualquer tipo de seleção para direcionar o professor ao estagiário, como mostra o trecho abaixo: 
E lá na escola tem professores efetivos em matemática e ele preferiu fazer comigo, então eu acredito que não tenha esse direcionamento da direção da escola em relação a com quem o estagiário vai fazer o estágio, mas no meu caso que sou de física, sou o único professor de física, então todos de física já obrigatoriamente fazem comigo (PEB01).

Ainda, confirma-se na fala do professor da escola, de que a escolha da escola pelos estagiários também está condicionada sumariamente ao tipo de ensino fornecido pela instituição escolar. Neste sentido, as escolas de "ensino regular" são buscadas com maior frequência do que as escolas de "ensino integral", a citar-se no trecho "Eu acredito que seja nesse sentido os que preferem ir pra Arno Hausser, mais por essa questão de localização e porque a escola e uma escola regular e daí ela é uma escola mais aberta assim, de eles fazerem o estágio na disciplina mesmo [...]" (PEB01).

Apesar da reduzida possibilidade do diálogo no ECSO, comprovouse que há experiências que indicam que os licenciandos e o professor da escola realizam processos de reflexão sobre a prática nas situações de planejamento, organização e ordenação de conteúdos trabalhados em aula. E, neste sentido, a ação do professor da escola situa-se na condição de nortear possíveis condições de contorno aos problemas.

E eles querem desenvolver essas horas, queriam organizar melhor, planejar essas horas de regência e daí eles estavam com algumas dificuldades em relação até ao currículo, de como deveriam ser trabaIhados os conteúdos, matriz curricular, aí eles pediram uma ajuda, e daí eu fui (PEB01).

Excepcionalmente, ainda há outras situações que também permitem a instauração de tais processos de reflexão, da qual pode citar-se a organização e reestruturação das sequências didáticas para realização de intervenções de etapas do trabalho de conclusão de curso.

É imprescindível citar que, apesar das condições pouco dialógicas entre professor da escola e estagiário, suas relações são restritas ao respeito mútuo, como expresso no excerto "Não temos nenhum problema de relacionamento, muito pelo contrário, a gente se respeita muito, trabalha certinho cada um na sua área" (PEB01). Porém, há dificuldades e problemas na condução e orientação dos estagiários, dentre a qual cita-se o desconhecimento de ações a serem realizadas no momento de intervenção pelo estagiário, constatada em “[...] como ele não é residente, aí nem sempre eu sei 
tudo sobre o que ele vai fazer na sala de aula. Então acontece de uma aula ou outra ele fazer alguma coisa que eu não estava sabendo, ou então ele fazer alguma coisa que eu não concorde muito [...]" (PEB01).

Ainda, do trecho "As partes difíceis, assim, de uma parte mais funcional seria o fato de que de vez enquanto eles faltam sem avisar [...]" (PEB01), corrobora-se a importância do diálogo entre os sujeitos do estágio, uma vez que as faltas em dias de estágio não se fazem comunicadas ao professor da escola. As faltas dos estagiários são frequentemente associadas aos demais compromissos da universidade, que são colocadas acima das necessidades do ECSO, que pode ser compreendida no trecho "Um outro problema é que eles têm os compromissos deles na Universidade, e eu sempre percebo que os compromissos da Universidade estão sempre acima dos compromissos da escola" (PEB01).

\begin{abstract}
A primeira sensação que eu tive quando os estagiários chegaram, foi assim "eita, pô, agora eu vou ter que dar aula top, galera vai está avaliando, vai tá só anotando tudo que eu estou falando, que eu estou fazendo", eu acho que essa foi a primeira sensação que eu tive em relação a quando eu recebi os estagiários (PEB01). E é de sua constituição que o professor da escola se agonia, incorrendo em suas atividades da docência um processo de tomada de comportamento profissional em conformidade às expectativas de outros, como fora explicitado em sua fala "[...] eu necessariamente teria que ser um bom professor porque estaria em avaliação" (PEB01).
\end{abstract}

O professor da escola básica, ao receber e acompanhar os estagiários admite condicionar sua prática docente no sentido do atendimento de expectativas, ou mesmo, em uma compreensão que se assemelha a uma autodefesa. De tal forma, evidencia-se que não há nenhum investimento sobre o professor da escola no que diz respeito a qualificação de suas ações no ECSO: "Ah não sei, é assim, eu não sei responder. Acho que sim, mas é porque não teve nenhum preparo e aconteceu muito assim, sabe? Muito 'agora tem estagiário'"' (PEB01).

E neste processo, o que se percebe é que o professor da escola constrói saberes parciais sobre as estruturas normativas do ECSO, e de mesma forma, sobre seu modo de comprometer-se com a formação do estagiário. Este professor realiza um exercício de memória, em que se posta a confrontar os aspectos curriculares do curso de licenciatura atual e o realizado por ele, como evidencia-se no trecho "[...] Eu tenho por três viés. $O$ viés de que já fui aluno da universidade; o viés de que mudou o currículo 
da universidade, não é mais o mesmo de quando eu formei, então eu dei uma olhadinha como tá agora; e o terceiro porque os alunos, eles me falam" (PEB01).

E logo, não há também orientações e planejamentos concretos, sistemáticos e evidenciados sobre as atividades do ECSO entre o professor da escola e o professor da universidade, como mostra o trecho "Não, não tem. Com os professores da universidade, não" (PEB01). Nota-se que ocorrem algumas reuniões na universidade, em que o professor da escola participou eventualmente, mas não para tratamento das ações do ECSO em que "Vez ou outra ela acontece na Unesp. Então havia alguns comentários, mas nunca houve uma reunião diretamente para falar sobre" (PEB01).

Sobre outros programas em que o professor e a escola se fazem participantes, notou-se em sua fala "Não... ah, não, espera, calma... é porque são oito residentes, mas eu acho que são seis estagiários, tem dois residentes que não são estagiários" (PEB01), que frequentemente as funções do estagiário e do residente são assemelhadas por este, pois vários dos licenciandos encontram-se atuantes tanto no ECSO quanto no programa Residência Pedagógica. E assim como o expresso pelo PEB01 "Vários dos estagiários são também residentes, e nós temos uma reunião semanal, ela ocorre toda sexta às duas horas da tarde", reafirma-se os argumentos dispensados anteriormente e que corroboram na afirmação de que as reuniões que envolvem estagiários e professor da escola não são exclusivas para o tratamento do ECSO.

Depreende-se que os estagiários contribuem para a diversificação da prática do professor da escola. Neste trecho da fala do professor que diz que "Então geralmente nós sempre tentamos estudar essas teorias, né, os teóricos, e de alguma forma inserir esses teóricos nos planos de aula, que era algo que eu não fazia, assim, de uma forma estudada antes, né?" (PEB01). Evidencia-se que os estagiários oportunizaram discussões sobre referenciais teóricos, que inseridos nos planos de aula, refletiram nas atividades de sala de aula.

O planejamento conjunto entre professor da escola e estagiário proporcionou trabalhos significativos, como a utilização de experimentos didáticos para o ensino de Física.

Sim. Experimentos, por exemplo, às vezes eu, tipo... a gente combina... eu, às vezes eu até peço: “ó, fulano, faz um experimento tal sobre tal tema”. Aí eu chego na aula, apresento, às vezes é ao contrário, às vezes apresento teoria, aí eles vão, fazem um experimento, eles 
tentam... geralmente, na maioria das vezes, eles tentam fazer de maneira investigativa com os alunos e daí apresentam um experimento, aí depois eu volto, aí faço algum exercício (PEB01).

Segundo o professor, os estagiários foram ativos no desenvolvimento destas atividades diversificadas, e acrescentaram-na à prática de ensino do professor. Ainda, o trabalho colaborativo entre estagiário e professor oportunizou o desenvolvimento de atividades que, visto o sucesso de sua promoção, deverão ocupar novos espaços e perpetuar-se na prática do docente da escola, como demonstra o excerto:

E daí nós fizemos algumas palestras com eles e daí foram os estagiários que fizeram essas palestras, e daí nós reservamos o laboratório de informática por uma semana praticamente, e daí nós passamos muito tempo lá incentivando eles a fazerem as inscrições do ENEM, vem pra USP, e daí provavelmente a gente vai continuar isso o ano todo (PEB01).

As atividades do estágio permitem, então, ao professor da escola colocar-se em um processo de releitura da docência, que o faz percorrer da historicidade de sua formação inicial aos aspectos contemporâneos dos cursos de formação aos quais provém os estagiários. Inclui-se nesse processo o autorreconhecimento de suas capacidades, sejam relacionadas ao ensino de alunos da educação básica, ou nas condições de formador de professores.

\section{Considerações Finais}

Argumentou-se neste texto que a formação continuada de professores/as da educação básica pode ocorrer via estágio curricular supervisionado obrigatório. Para tanto, buscou-se por meio das vozes dos professores da escola básica captar o que aprendem os professores da escola que participam ou participaram de experiências de Estágio Curricular Supervisionado Obrigatório, como traduziram em novas práticas ou em saberes docentes, e as ações e relações proporcionadas entre os sujeitos das instituições envolvidas no estágio.

Neste sentido, identificou-se elementos e ações desenvolvidas no âmbito do ECSO que o sustentam como um processo formativo para o professor da escola de educação básica. Assim, constatou-se a predominância 
de "atividades voltadas ao ensino" que diversificaram a prática do professor durante o estágio. As "trocas de experiências", os "diálogos", as "conversas", o "planejamento", os "experimentos demonstrativos de Física", "as curiosidades", a "reciclagem", os "estudos da teoria", são alguns dos termos anunciados pelos professores da escola frente ao estágio e em contribuição a si e a sua prática. Estas atividades, realizadas em parceria, e por vezes, elaboradas e sugeridas pelos estagiários quando oportunizada sua participação ativa e intencional, representam ao professor da escola a possibilidade de reestruturação da prática.

Desvelou-se nesta pesquisa que, não são oportunizadas formas institucionalizadas, a partir da universidade como instituição propositora, de formação ao professor da escola que atua no Estágio Curricular Supervisionado Obrigatório. Se faz necessário, então, o estabelecimento de um projeto institucionalizado de estágio que credite em sua estrutura, objetivos direcionados a outras oportunidades aos professores da escola. Por outro lado, percebe-se nesta pesquisa os sentidos atribuídos sobre a universidade, de uma visão de "autossuficiência" do professor da escola no estágio. Esta visão, contida na cultura do estágio e que atrapalha a extensibilidade do termo "formação continuada pelo estágio", remete-se também a uma compreensão de que a procura por melhores condições formativas do professor da escola deve partir do sujeito que a recebe e não da universidade.

\section{Referências}

AGUIAR, Wanda Maria J.; OZELLA, Sergio. Núcleos de significação como instrumento para a apreensão da constituição dos sentidos. Psicologia: Ciência e Profissão, Brasília, v. 26, n. 2, p. 222-245, jun. 2006.

$\therefore$. Apreensão dos sentidos: aprimorando a proposta dos núcleos de significação. Revista Brasileira de Estudos Pedagógicos, Brasília, v. 94, n. 236, p. 299-322, jan./abr. 2013.

AGUIAR, Wanda Maria J.; Soares, J. R.; Machado, V. C. Núcleos de significação: uma proposta histórico-dialética de apreensão das significações. Cadernos de Pesquisa, 45(155),56-75. 2015.

ANDRÉ, Marli. Técnicas qualitativas e quantitativas de pesquisa - oposição ou convergência. Cadernos CERU, n. 3, série II, p. 161-165, 1991. 
ANTUNES, Denise Dalpiaz; PLASZEWSKI, Helenara. O ser professor em contínua construção. Educação, v. 41, n. 1, p. 30-40, Porto Alegre-RS, jan./abr. 2018.

AROEIRA, Kalline Pereira. Estágio supervisionado e formação contínua: possibilidades para a reflexão da prática docente na área de educação física. In: VIII Encontro de Pesquisa em Educação da Região Sudeste, ANPED, Vitória-ES, 2007.

BELEI, Renata Aparecida et. al. O uso de entrevista, observação e videogravação em pesquisa qualitativa. Cadernos de Educação, Pelotas, v. 30, n. 187-199, jan./jun. 2008.

BENITES, Larissa Cerignoni. 0 professor-colaborador no estágio curricular supervisionado em educação física: perfil, papel e potencialidades. 2012. Tese (Doutorado) - Instituto de Biociências de Rio Claro, Universidade Estadual Paulista, Rio Claro-SP, 2012.

BENITES, Larissa C; CYRINO, Marina; NETO, Samuel de Souza. A prática de ensino como possibilidade de reflexão: concepções dos professorescolaboradores. In XVI ENDIPE - ENCONTRO NACIONAL DE DIDÁTICA E PRÁTICAS DE ENSINO, 2012. Campinas - sp, Anais..., Campinas. SP, 2012.

BENITES, Larissa Cerignoni; SARTI, Flavia Medeiros; NETO, Samuel de Souza. De mestres de ensino a formadores de campo no estágio supervisionado. Cadernos de Pesquisa. v.45, n.155, p.100-117, jan./mar. 2015

CAIRES, Susana; MOREIRA, Maria Alfredo; ESTEVES, Carla Hiolanda; VIEIRA, Diana A. As vivências e percepções dos actores na formação inicial de professores: a figura do supervisor cooperante. Revista Portuguesa de Educação, 24(2), pp. 59-79, CIEd - Universidade do Minho, 2011.

CALDERANO, Maria da Assunção. Tecendo relações entre teses e ações desenvolvidas por professores supervisores de estágio curricular. 36a REUNIÃO NACIONAL DA ANPED, 2013, Goiânia- GO. Anais..., Golânia, 2013.

CYRINO, M.; NETO, S. S. Interventoria: uma proposta para o acompanhamento de estagiários de pedagogia. Formação Docente - 
Revista Brasileira de Pesquisa sobre Formação de Professores, v. 5, n. 8, p. 136-152, 30 jun. 2013.

CYRINO, Marina; CERIGNONI Benites, Larissa; de Souza NETO, Samuel. Formação Inicial em Pedagogia: os professores colaboradores no Estágio Supervisionado. Educação Unisinos. v. 19, n. 2, maio/ago. 2015.

DIAS, Aurora; VIEIRA, Celina Tenreiro. A Supervisão na Formação Contínua de Professores de Matemática e o Desenvolvimento Profissional. Bolema. Rio Claro-SP, v. 26, n. 42A, p. 65-86, 2012.

GALINDO, Mônica Abrantes; ABIB, Maria Lucia Vital dos Santos. Escola, universidade e estágio supervisionado: sentidos atribuídos pelos professores das escolas básicas. XVI ENDIPE - ENCONTRO NACIONAL DE DIDÁTICA E PRÁTICAS DE ENSINO, 2012, Campinas, Anais... , Campinas, Unicamp, 2012

GHEDIN, Evandro. Professor reflexivo: da alienação da técnica à autonomia da crítica. Selma Garrido Pimenta, Evandro Ghedin (orgs). Professor reflexivo no Brasil: gênese e crítica de um conceito. 4. ed. São Paulo. Cortez. 2006.

GUNTHER, Hartmut. Pesquisa qualitativa versus pesquisa quantitativa. Psic.: Teor. e Pesq., Brasília, v. 22, n. 2, p. 201-210, maio/ago. 2006.

LIMA, Maria Socorro Lucena. Reflexões sobre o estágio/prática de ensino na formação de professores. Rev. Diálogo Educ., v. 8, n. 23, p. 195-205, Curitiba, jan./abr. 2008.

MINAYO, Maria Cecília de S.; SANCHES, Odécio. Quantitativo-qualitativo: oposição ou complementaridade? Cad. Saúde Públ., Rio de Janeiro, p. 239262. jul./set. 1993.

PIMENTA, Selma Garrido. Professor reflexivo: construindo uma crítica. In: PIMENTA, Selma Garrido; GHEDIN, Evandro (orgs). Professor reflexivo no Brasil: gênese e crítica de um conceito. 4. ed. São Paulo, Cortez, 2006.

PIMENTA, Selma Garrido. LIMA, Maria do Socorro Lucena. Estágios supervisionados e o Programa Institucional de Bolsa de Iniciação à 
Docência: duas faces da mesma moeda? Revista Brasileira de Educação, v. 24, 2019.

SARTI, F. M. Parceria intergeracional e formação docente. Educação em Revista, Belo Horizonte, v. 25, n. 2, p. 133-152, 2009.

SARTI, Flavia Medeiros; ARAÚJO, Simone Reis Palermo Machado. Acolhimento no estágio supervisionado: entre modelos e possibilidades para a formação docente. Revista Educação, v. 39, n. 2, Porto Alegre, maio/ago. 2016.

TRIVIÑOS, Augusto. N. S. Introdução à pesquisa em Ciências Sociais: A pesquisa qualitativa em educação. São Paulo, Atlas, 1987. 